\title{
UAV-Assisted Thermal Infrared and Multispectral Imaging of Weed Canopies for Glyphosate Resistance Detection
}

\author{
Austin Eide ${ }^{1}$, Cengiz Koparan ${ }^{1}\left(\mathbb{D}\right.$, Yu Zhang ${ }^{1}$, Michael Ostlie ${ }^{2}$, Kirk Howatt ${ }^{3}$ and Xin Sun ${ }^{1, *(1)}$ \\ 1 Department of Agriculture and Biosystems Engineering, North Dakota State University, Fargo, \\ ND 58108-6050, USA; austin.j.eide@ndus.edu (A.E.); cengiz.koparan@ndsu.edu (C.K.); \\ yu.zhang.7@ndsu.edu (Y.Z.) \\ 2 NDSU Carrington Research Extension Center, Carrington, ND 58421-0219, USA; mike.ostlie@ndsu.edu \\ 3 Department of Plant Sciences, North Dakota State University, Fargo, ND 58108-6050, USA; \\ kirk.howatt@ndsu.edu \\ * Correspondence: xin.sun@ndsu.edu; Tel.: +1-701-231-5756
}

Citation: Eide, A.; Koparan, C.; Zhang, Y.; Ostlie, M.; Howatt, K.; Sun, X. UAV-Assisted Thermal Infrared and Multispectral Imaging of Weed Canopies for Glyphosate Resistance Detection. Remote Sens. 2021, 13, 4606. https://doi.org/10.3390/rs13224606

Academic Editors: Giuseppe Modica and Karem Chokmani

Received: 18 September 2021

Accepted: 13 November 2021

Published: 16 November 2021

Publisher's Note: MDPI stays neutral with regard to jurisdictional claims in published maps and institutional affiliations.

Copyright: (c) 2021 by the authors. Licensee MDPI, Basel, Switzerland. This article is an open access article distributed under the terms and conditions of the Creative Commons Attribution (CC BY) license (https:/ / creativecommons.org/licenses/by/ $4.0 /)$.

\begin{abstract}
The foundation of contemporary weed management practices in many parts of the world is glyphosate. However, dependency on the effectiveness of herbicide practices has led to overuse through continuous growth of crops resistant to a single mode of action. In order to provide a cost-effective weed management strategy that does not promote glyphosate-resistant weed biotypes, differences between resistant and susceptible biotypes have to be identified accurately in the field conditions. Unmanned Aerial Vehicle (UAV)-assisted thermal and multispectral remote sensing has potential for detecting biophysical characteristics of weed biotypes during the growing season, which includes distinguishing glyphosate-susceptible and glyphosate-resistant weed populations based on canopy temperature and deep learning driven weed identification algorithms. The objective of this study was to identify herbicide resistance after glyphosate application in true field conditions by analyzing the UAV-acquired thermal and multispectral response of kochia, waterhemp, redroot pigweed, and common ragweed. The data were processed in ArcGIS for raster classification as well as spectral comparison of glyphosate-resistant and glyphosate-susceptible weeds. The classification accuracy between the sensors and classification methods of maximum likelihood, random trees, and Support Vector Machine (SVM) were compared. The random trees classifier performed the best at 4 days after application (DAA) for kochia with $62.9 \%$ accuracy. The maximum likelihood classifier provided the highest performing result out of all classification methods with an accuracy of $75.2 \%$. A commendable classification was made at $8 \mathrm{DAA}$ where the random trees classifier attained an accuracy of $87.2 \%$. However, thermal reflectance measurements as a predictor for glyphosate resistance within weed populations in field condition was unreliable due to its susceptibility to environmental conditions. Normalized Difference Vegetation Index (NDVI) and a composite reflectance of $842 \mathrm{~nm}$, $705 \mathrm{~nm}$, and $740 \mathrm{~nm}$ wavelength managed to provide better classification results than thermal in most cases.
\end{abstract}

Keywords: weed identification; glyphosate; thermal image; multispectral image; UAV

\section{Introduction}

Herbicide usage provides crop producers with multiple benefits, including increased crop yield, timely and affordable management, reduced weed pressure, and reduction in soil structure degradation caused by conventional tillage methods [1-3]. Scientific advancements in the 1990s supported the development of a transgenic herbicide-resistant soybean varieties that allowed crop producers to spray broad-spectrum herbicides to kill weeds with no concern of harming their crops [4]. However, dependency on the effectiveness of herbicide applications has led to overuse through continuous growth of herbicide-resistant crops and the application of the associated weed control agent [5]. In $2010,93 \%$ of all soybeans grown in the USA were herbicide-resistant, as were $78 \%$ of 
all cotton and $70 \%$ of all maize varieties [6]. This overuse has caused genetic shifts in weed populations resulting in the success of resistant biotypes [7,8]. Studies estimate that herbicide-resistant management (HRM) has increased herbicide costs in states such as Iowa by $\$ 20-40$ per acre from 2013-2017 [9].

Glyphosate ( $\mathrm{N}$-phosphonomethyl-glycine) is one of the most common herbicides in production agriculture [10]. Developed in 1974, glyphosate is a non-selective herbicide that inhibits the enzyme enolpyruvyl shikimate-3-phosphate synthase (EPSPS) from developing amino acids required for protein synthesis [11]. Additional symptoms of glyphosate application include photosynthetic rate reduction, inhibition of growth, and chlorosis of plant tissue [12]. The highly effective herbicide quickly established widespread use by crop producers, accelerating the evolution of resistance mechanisms within weeds [13]. Moderate resistance is achieved in some weeds by mutations that occur at the targeted enzyme. However, in some species the translocation of glyphosate through the nontargeted parts of the plants (i.e., plant leaves) reduces the herbicide's ability to reach the root and apical meristems where the inhibition of EPSPS can occur [6].

Distinguishing susceptible and resistant populations of weeds is a challenging task. Prior to herbicide application, there is no significant difference in the visual appearance of resistant and susceptible weeds of the same species that can be noted during scouting [14]. Hyperspectral systems to detect differences between resistant and susceptible biotypes show potential in controlled environments, but their effectiveness is drastically reduced once introduced to field conditions [15]. Lab testing for an accumulation of shikimic acid within plant leaves is one method used to identify glyphosate resistance, but its lack of practicality does not justify its use in large scale applications [16]. The development of a method that can indicate herbicide resistance within an acceptable timeframe after application has great potential to help growers manage their fields more effectively [17].

Researchers at North Dakota State University (NDSU) pursued an alternative method of herbicide resistance detection that utilized thermal imaging technology [18]. Thermal imaging has shown potential in detecting plant canopies that are experiencing increased levels of stress and reduced rates of photosynthesis [19]. The application of glyphosate to susceptible plants causes a reduced photosynthetic rate due the inhibition of stomatal conductance [20]. The reduction in stomatal activity lowers the ability for transpiration of water to be performed within the plant leaf, therefore resulting in increased leaf temperature [21]. The study hypothesized glyphosate-susceptible plant canopies would emit a significantly higher temperature than resistant canopies and that the temperature differences could be recorded using a thermal imager. It was reported that glyphosate-susceptible populations of ragweed, waterhemp, and kochia had higher canopy temperatures in comparison to resistant populations after glyphosate [22]. The canopy temperature values were then used to train a support vector machine (SVM) classifier that could identify the weeds that exhibited glyphosate resistance with accuracies exceeding $90 \%$ for all three species [18].

Subsequent greenhouse studies were performed with the objective of validating the hypothesis that glyphosate-resistant weeds can be identified using thermal imagery [18]. In these studies, glyphosate was applied to populations of waterhemp, kochia, common ragweed, and redroot pigweed and monitored with hourly image captures from a thermal camera [22]. The weeds selected were determined to be most relevant to North Dakota agriculture and showed the most potential for glyphosate resistance [23-25]. The SVM classification strategy was once again utilized to validate the original findings as well as one tailed t-testing to investigate if glyphosate-susceptible weeds consistently maintained higher canopy temperatures than glyphosate-resistant weeds.

Analogous to thermal sensing, multispectral sensing is also used extensively within agriculture [26-28]. Multispectral sensing is the practice of using one sensor to image multiple areas of the light spectrum at the same time [29]. When paired with Unmanned Aerial Vehicle (UAV), multispectral sensing payloads have proven to be powerful detectors of biophysical characteristics of vegetation during the growing season [30]. Multispectral cameras capture image data within specified wavelengths of the electromagnetic spectrum, 
most commonly in the blue, green, red, red-edge, and near-infrared (NIR) wavelengths. However, some sensors such as the Micasense Red-Edge MX Dual Camera are capable of capturing up to ten different wavelengths including visible and non-visible, instantaneously [31].

The high spatial and spectral resolution provided by UAV-assisted multispectral cameras can be used for a variety of agricultural applications including high-throughput phenotyping, disease identification and severity analysis, nutrient management, and weed identification and mapping [32,33]. Rapid identification of plant height, canopy cover, vegetation index, and flowering stage was performed in cotton fields to enhance breeding using multispectral images over multiple stages of the growing season [34]. Potato late blight disease severity was measured using leaf and canopy measurements from the red and red-edge wavelengths with classification accuracies as high as 89.33\% [35]. Optimal, site specific, nitrogen fertilizer rate was investigated by Thompson and Puntl. Their use of multispectral sensors reduced nitrogen application rates by approximately $31 \mathrm{~kg} \mathrm{~N} \mathrm{ha}{ }^{-1}$ without causing yield losses and improved nitrogen use efficiency by as much as $18 \%$ [36]. Finally, computational deep learning with multispectral images provided a practical solution to identifying weeds in a sugarbeet field by detecting subtle differences in shapes and reflectance patterns of their leaf canopies [37].

The introduction of newer, higher resolution thermal imaging systems that are compatible with UAVs have boosted the practical use of thermography in agriculture [38-41]. UAV thermal remote sensing applications include monitoring plant water stress, detection of diseases, and plant phenotyping [42-44]. It was reported that UAV thermal sensing could also offer remote sensing data for orchard management including water management by observing the fruit-tree canopy temperature variations [45-47]. Remote thermal sensing could enable real-time site-specific management techniques such as crop and weed identification, yield prediction, and crop stress assessment when combined with machine learning $[46,48]$. Thermal measurement as complementary to other sensor measurements such as hyperspectral, visible, and optical distance has also proved to be more effective on field scale crop phenotyping [49-51]. In example, complementary sugar beet canopy temperature measurements with UAV infrared and Red, Green, and Blue (RGB) measurements were proved to improve the accuracy of UAV thermal measurements at altitudes below $40 \mathrm{~m}$ [52]. Another direct use of UAV thermal remote sensing can be given as nitrogen fertilization management with spatial clustering models [53,54]. Most of these applications are used to monitor crops, and the investigation of other types of vegetation within agricultural systems is needed. Weed control is a critical component in large-scale farming and the unexplored potential of thermal imagery using UAVs could boost the capabilities of site-specific weed management technology [55]. Therefore, the UAV-assisted thermal imagery could be used as a practical solution to identify glyphosate-susceptible and glyphosate-resistant weed populations based on canopy temperature. Particularly, the study in this paper extends the work previously accomplished in greenhouse environment to a field evaluation [22].

The objective of this study was to identify herbicide resistance after glyphosate application in true field conditions by analyzing the thermal and multispectral response of weed species of waterhemp (Amaranthus rudis), kochia (Kochia scoparia), common ragweed (Ambrosia artemisiifolia), and redroot pigweed (Amaranthus retroflexus).

\section{Materials and Methods}

\subsection{Experiment Site and Data Collection}

The experiment was conducted at two locations. One location was the NDSU Agronomy Seed Farm in Casselton, ND, USA while the other was conducted at the NDSU Research and Extension Center in Carrington, ND, USA (Figure 1). Each location contained a plot measuring approximately $33 \mathrm{~m}$ in length and $3.5 \mathrm{~m}$ in width $\left(115 \mathrm{~m}^{2}\right)$. Data collections were performed from the middle to end of August 2020 while all the plants were in vegetative growth stage. At the Casselton location, a combination of Roundup Ready 
2 Xtend and ND Stutsman conventional soybean was planted in alternating fashion in 4 rows with $76 \mathrm{~cm}$ (30 inch) row spacing. A center-pivot irrigation system was not available at this site, so water was provided to the weed plants using a truck-mounted water tank.
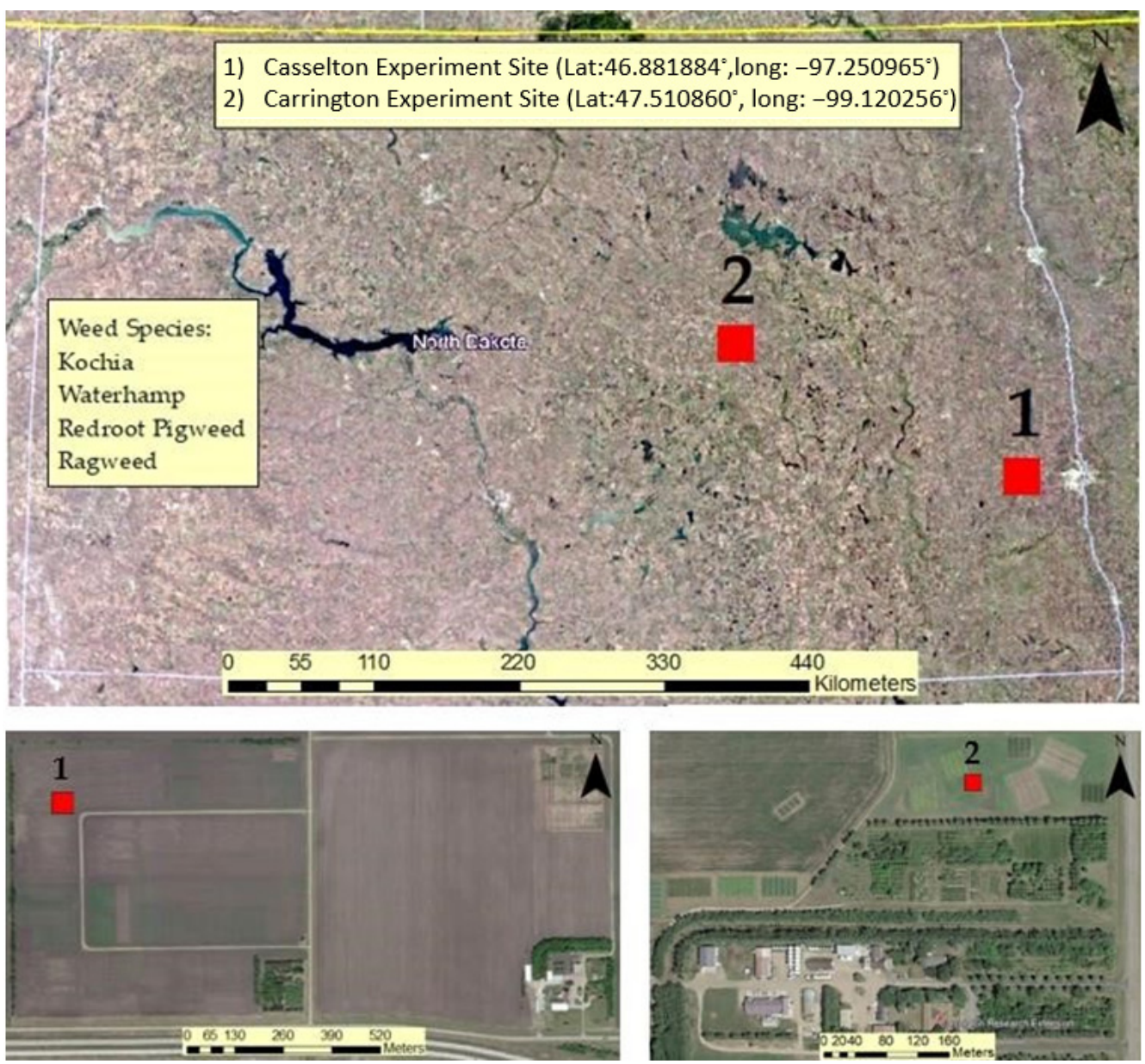

Figure 1. NDSU experiment sites represented in maps including weed species (top); (1) Casselton experiment site (bottom left) and (2) Carrington Experiment site (bottom right).

At this location, the soil series was predominantly Kindred-Bearden silty clay loams that are somewhat poorly drained and nonsaline [56]. Buckets of soil were collected at the location and brought to the Agricultural Experiment Station Greenhouse at the NDSU campus in Fargo, ND to be autoclaved. Once the autoclave process was complete, the soil was used to germinate the weed populations in greenhouse conditions at another location on campus. The soil was distributed into $9 \mathrm{~cm}$ square pots with $13 \mathrm{~cm}$ height and weed seeds were placed at approximately $3 \mathrm{~cm}$ soil depth. A total of 60 kochia plants, 60 waterhemp plants, 60 redroot pigweed plants, and 30 ragweed plants were successfully grown and transplanted to the field (Figure 1). To increase plant population, a selection of naturally occurring ragweed plants was transplanted from site location and introduced to the plot, resulting in a total number of 59 ragweed plants. The weed populations were comprised equally of two different biotypes, one being selected for glyphosate resistance and the other for glyphosate susceptibility. Glyphosate-susceptible waterhemp was not available when the experiment was conducted, so redroot pigweed was used as a surrogate. Plants were organized in a randomized complete block design based on their believed resistance status and planted in between the soybean rows with one species occupying a single row at a time. When the weeds were approximately $12-15 \mathrm{~cm}$ tall, $2 \mathrm{~L} / \mathrm{ha}$ of Roundup Powermax (48.7\% glyphosate) with Class Act NG at $2 \% v / v$ was applied to induce symptomology on the susceptible biotypes. 
At the Carrington location, five rows of Roundup Ready 2 Xtend (Bayer, Whippany, NJ, USA) Soybeans (Glycine Max) were planted with $76 \mathrm{~cm}$ row spacing. A center pivot irrigation system at this location was utilized to provide a constant water source for the plot. The soil series present at this location is predominantly Heimdal-Emrick (G229B) loams which are well drained and slightly saline [57]. Buckets of soil were also collected at this location and brought to the Agricultural Experiment Station Greenhouse at NDSU in Fargo, ND to be autoclaved. The soil was then returned to a greenhouse located at the Carrington location where weed populations were grown in $8 \mathrm{~cm}$ diameter pots. A total of 60 kochia plants, 60 waterhemp plants, 60 redroot pigweed plants, and 30 ragweed plants were successfully grown and then transplanted to the field plot in randomized fashion. When the weeds were approximately $12-15 \mathrm{~cm}$ tall, $2 \mathrm{~L} / \mathrm{ha}$ of Roundup Powermax (48.7\% glyphosate) with Class Act NG at $2 \% v / v$ was applied to induce symptomology on the susceptible biotypes.

\subsection{UAV Equipment and Flight Parameters}

Image data collection from the experiment sites was performed using a Zenmuse XT2 RGB/Thermal camera (DJI Technology Co., Ltd., Shenzhen, China) and a Micasense Red-Edge MX Dual camera System (Micasense, Seattle, WA, USA). The Zenmuse XT2 provided both RGB and thermal image data, but only the thermal image data were used for testing. The Red-Edge MX Dual camera system provided ten bands of spectral data. Imagers on the dual camera provided a selection of imagery around the blue, green, red, red-edge, and NIR wavelengths. Both systems were mounted simultaneously on a DJI M600 Pro UAV (DJI Technology Co., Ltd., Shenzhen, China).

Due to restrictions with the flight planning software, simultaneous image capture for both systems could not be performed at an altitude less than $25 \mathrm{~m}$. In addition, the Zenmuse XT2 had lower pixel resolution than the Red-Edge MX Dual camera requiring lower altitude flights for thermal image collection for proper image processing. Therefore, an $8 \mathrm{~m}$ manual flight was conducted solely using the Zenmuse XT2 while separate automated flights were performed at $10 \mathrm{~m}$ while capturing imagery with the Red-Edge MX Dual Camera system. Automated flights for the Red-Edge MX Dual Camera were planned and performed using Pix4D capture mobile app on iOS. This approach allowed for greater spatial resolution with the thermal camera, as the XT2 has a lower resolution than the Red-Edge MX Dual Camera system. Image data captured with the Red-Edge MX Dual Camera were calibrated using a provided reflectance panel from Micasense to transform raw pixel values to absolute reflectance. Imagery was captured at 4 and 6 DAA at both locations. An extra flight was performed 8 DAA at Casselton. Undesired weather conditions at the Carrington site during the 8 DAA time period prevented a flight from being performed. The weather conditions for each flight are listed in Table 1 . The weather conditions during the remaining data collection times were mostly free of clouds, at most sparsely cloudy.

Table 1. Weather conditions during data collection.

\begin{tabular}{cccccc}
\hline \multirow{2}{*}{ Site } & $\begin{array}{c}\text { Days after } \\
\text { Application }\end{array}$ & $\begin{array}{c}\text { Collection } \\
\text { Time }\end{array}$ & $\begin{array}{c}\text { Air Temp } \\
\left({ }^{\circ} \mathbf{C}\right)\end{array}$ & $\begin{array}{c}\text { Relative } \\
\text { Humidity (\%) }\end{array}$ & $\begin{array}{c}\text { Solar Radiation } \\
\text { (Lys) }\end{array}$ \\
\hline \multirow{3}{*}{ Casselton } & 4 & $10: 30-11: 30$ & 21.77 & 74 & 14.5 \\
& 6 & $10: 30-11: 30$ & 23.31 & 55 & 61 \\
\hline \multirow{2}{*}{ Carrington } & 8 & $10: 30-11: 30$ & 22.68 & 77.5 & 37.5 \\
& 4 & $10: 30-11: 30$ & 23.73 & 65 & 52 \\
\end{tabular}

Georeferencing for the imagery was performed by the inclusion of ground control points (GCPs). The GCPs consisted of white 5-gallon bucket lids with colored stakes driven through the center of them to provide a distinct center point. A Trimble Geo-7x Handheld Data Collector and Zephyr 3 for Global Positioning System (GPS) antenna (Trimble Geospatial, Westminster, Sunnyvale, CA, USA) was then used to capture the GCP locations with $2 \mathrm{~cm}$ accuracy. Five GCPs were placed at each site with four points at 
the field corners and one point at the center. In cases where thermal imagery was being captured, cold water was placed over the bucket lids to be easily visible in the imagery. In addition to GCP collection, GPS data were collected from the approximate centroid of each plant location for later use in mapping software.

Imagery was stitched into reflectance ortho-mosaics using Pix4Dmapper (Pix4D, Prilly, Switzerland). NIR $(668 \mathrm{~nm})$ and red $(840 \mathrm{~nm})$ wavelength imagery from the Red-Edge MX Dual Camera system were used to generate an additional Normalized Difference Vegetation Index (NDVI) mosaic. Approximately 150-200 image captures were taken per flight and used for mosaic generation. Ground control point data from the Trimble GPS were incorporated in the processing procedure to grant spatial accuracy as high as $2 \mathrm{~cm}$. A complete list of flight operations and equipment parameters is summarized in Table 2.

Table 2. Unmanned Aerial Vehicle (UAV) flight operation summary.

\begin{tabular}{|c|c|c|}
\hline \multirow{2}{*}{ Equipment and Parameters } & \multicolumn{2}{|c|}{ Camera Type } \\
\hline & Multispectral & Thermal \\
\hline UAV Model & \multirow{5}{*}{$\begin{array}{c}\text { DJI M600 } \\
\text { Micasense Red-Edge Dual Camera } \\
1280 \times 960 \\
5.4 \mathrm{~mm} \\
444,475,531,560,650,668,705,717,740,842 \\
(\mathrm{~nm})\end{array}$} & DJI M600 \\
\hline Sensor & & Zenmuse XT2 Thermal Camera \\
\hline Pixel Resolution & & $640 \times 512$ \\
\hline Focal Length & & $25 \mathrm{~mm}$ \\
\hline Channels & & $7.5-13.5(\mu \mathrm{m})$ \\
\hline Average altitude & $10 \mathrm{~m}$ & $8 \mathrm{~m}$ \\
\hline Ground Spatial Distance & $0.71 \mathrm{~cm}$ & $1.03 \mathrm{~cm}$ \\
\hline Forward overlap & $75 \%$ & $+80 \%$ \\
\hline Side overlap & $75 \%$ & $+80 \%$ \\
\hline FOV & $47.2^{\circ} \mathrm{HFOV}$ & $25^{\circ} \mathrm{HFOV}$ \\
\hline
\end{tabular}

\subsection{Extraction of Vegetation and Development of Classification Zones}

Once the images were gathered from the experiments, they were processed into mosaics before visualizing in ArcGIS Pro (ESRI, Redlands, CA, USA). The plant GPS data were then overlaid as point shapefiles. The Buffer tool in ArcGIS Pro was then used to create $12 \mathrm{~cm}$ buffer shapefiles around the centroid of the pots. The buffer size selection was empirical and it was decided by the specialists at NDSU. Buffers were inspected for accurate placement in the imagery and corrected if necessary. Buffers were then selected and separated into their own respective species using the Clip tool. The visual survival evaluation results were then added to the shapefile attribute table to further separate the buffers into resistant and susceptible biotypes within each species.

The buffers were then used to extract $12 \mathrm{~cm}$ diameter raster information from each image dataset, vastly reducing the amount of imagery so that only the plant locations would be subjected to further processes. This approach, however, still left a mixture of soil and vegetation within the buffers. To increase the extraction accuracy even further, the Extract by Attributes tool was used to extract pixels from the buffers that had an NDVI value greater than 0.4 . This action removed the soil from the buffers so that only vegetation would be displayed. The NDVI output was then used to remove soil pixels from the thermal and multispectral raster using the Extract by Mask tool. The complete extraction process is illustrated in Figure 2.

Sets of buffers were created for each species and separated into six classes based on their resistance status. The classification was made as magnitude of glyphosate resistance where zero indicated dead plants while five indicated plants with no symptoms. The magnitude of resistance (MoR) indicated increasing resistance as the numbers go up from zero to five where one indicating more symptoms while four indicating lesser symptoms on plants.

In addition to thermal extraction from the Zenmuse XT2, extractions of NDVI and a 3-band composite image from the Red-Edge MX Dual Camera system were also made to serve as comparisons. By using the Spectral Profile tool within ArcGIS, the reflectance of 
glyphosate-resistant vegetation and glyphosate-susceptible vegetation were compared at each of the ten bands provided by the Red-Edge MX Dual Camera system.

a)

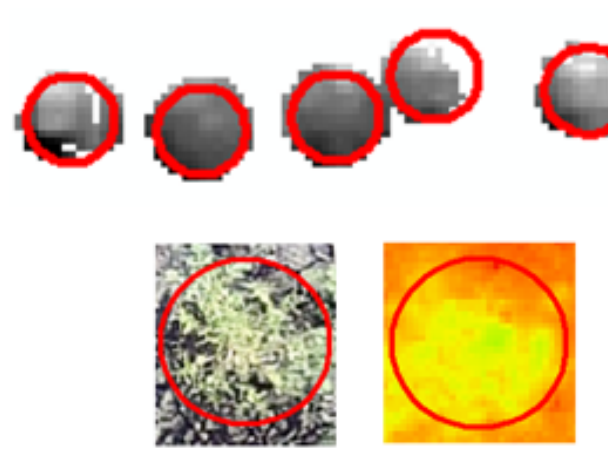

(b) (c)

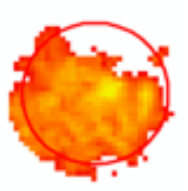

(d)
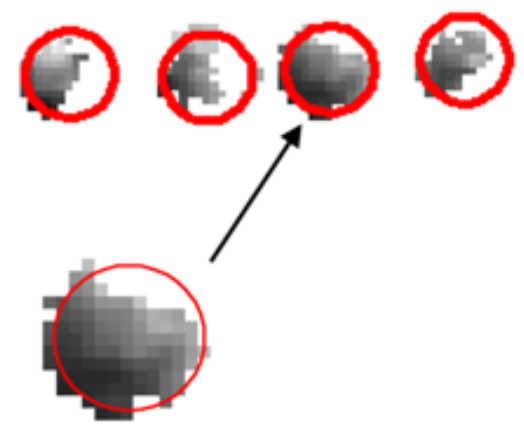

Figure 2. The complete extraction process: (a) Extracted thermal data from kochia at the Casselton location. (b) RGB image of kochia for reference. (c) NDVI of kochia prior to 0.4-pixel value extraction. (d) NDVI mask containing pixels that score over 0.4 (e) NDVI mask applied to thermal data.

\subsection{Raster Classification of Glyphosate-Resistant and Glyphosate Susceptible Weeds}

Once the buffered and extracted datasets were created, they were then classified using the Image Classification Wizard in ArcGIS Pro. Training zones were created over the plant locations using the buffer shapefiles that were separated based upon resistance status and then conjoined to create a training template containing two classes: glyphosate-susceptible vegetation and the other being glyphosate-resistant vegetation. Each classification was performed on each species independent from one another except in the case of waterhemp and redroot pigweed. In addition to weed classifications, a classification was made between the Round-up Ready soybean and conventional Stutsman soybean at Casselton 8 DAA to see if thermal classification performance could be greatly improved when dealing with known opposing MoR ratings.

Pixel based image analysis was used to classify the biotypes. Three classification methods were used to classify each species raster dataset for each of the three days. Data were collected to compare classification accuracy between the imaging systems and classification methods. Maximum likelihood, random trees, and support vector machine were the three classification methods used [58-60]. The support vector machine classification method utilized only a subset of the pixels included in the raster datasets to act as training data for the classifier. The maximum samples per class was set to the default value of 500 pixels for each class. The random trees classifier similarly used only a subset of pixels but with a default value of 1000 pixels.

\subsection{Accuracy Assessments of Thermal, NDVI, and Wavelength Composite Classifications}

To test the accuracy of the generated classifications, the Create Accuracy Assessment tool within ArcGIS Pro was used to digitize ground truth points within each classification raster's extents. Pixels that belonged to plants that were determined to be glyphosatesusceptible within the survival evaluation were assigned the value of 0 , while pixels that belonged to a glyphosate-resistant plant were assigned a value of 1 . Approximately 1000 points were used for every species. The points were then updated by recording the values of the point locations observed in the classification raster, which provided a shapefile with both ground truth and classification fields with raster values ranging from $0-1$. The Compute Confusion Matrix tool was then used to observe the accuracy and kappa coefficient of each classification attempt. Figure 3 showed the image processing and prediction analysis steps for the weed classification in this study. 


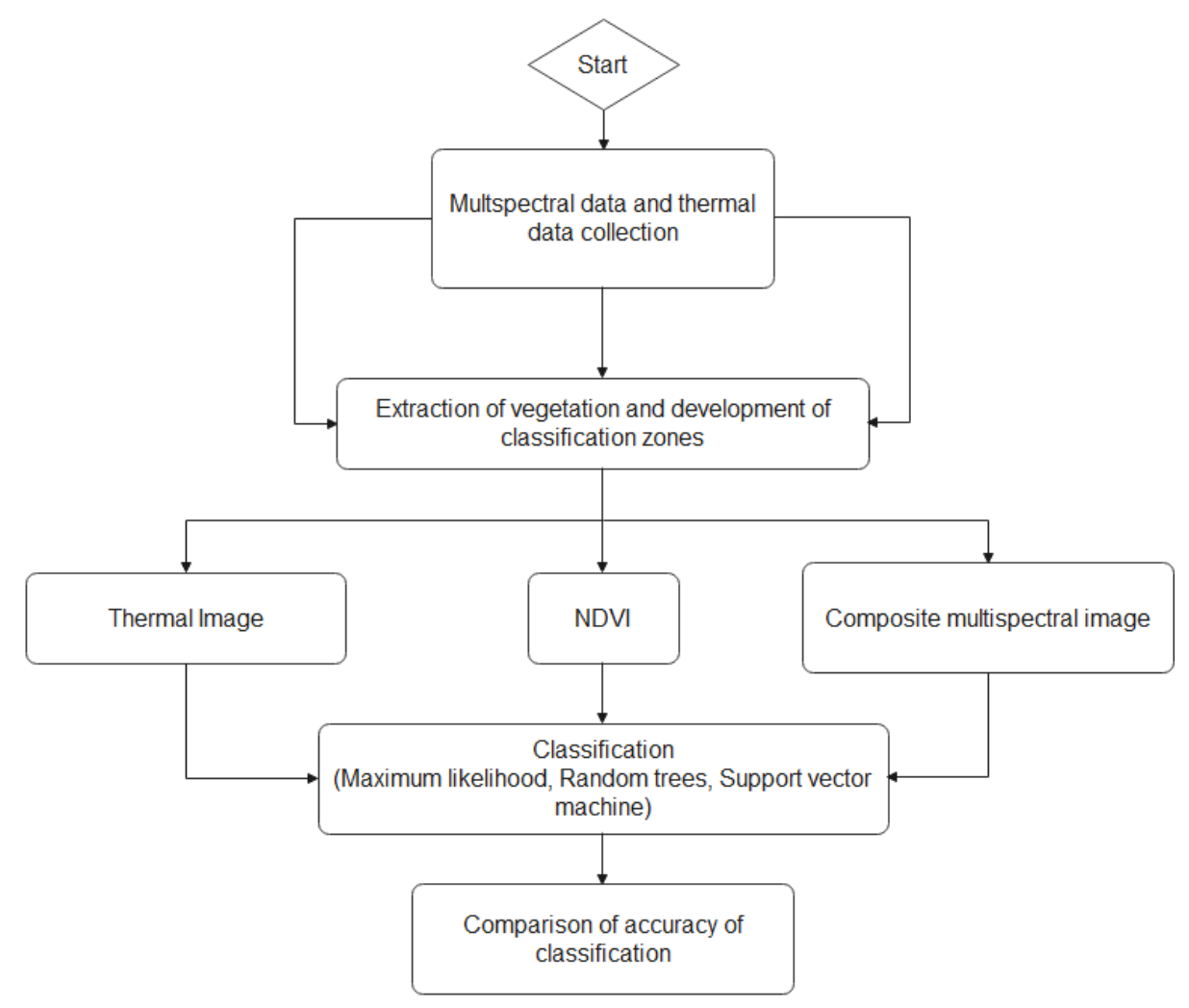

Figure 3. Image processing and predicition analysis steps for weed classification.

\section{Results and Discussion}

\subsection{Post-Experiment Evaluation and Comparisons}

Post-experiment visual evaluations that were performed 14 days after application (14 DAA) showed that varying degrees of glyphosate resistance occurred in the species. The MoR observed at the Casselton location are summarized where weeds are grouped based on their resistance status. Plants with MoR equal to or greater than 3 were considered resistant (Res) (Table 3).

Table 3. Casselton Plant Survival Evaluation at 14 DAA.

\begin{tabular}{ccccccccc}
\hline \multirow{2}{*}{ Species Rating } & \multicolumn{4}{c}{ Magnitude of Resistance } & \multicolumn{2}{c}{ \# Observed } \\
\cline { 2 - 8 } & $\mathbf{0}$ & $\mathbf{1}$ & $\mathbf{2}$ & $\mathbf{3}$ & $\mathbf{4}$ & $\mathbf{5}$ & Susc. & Res. \\
\hline Kochia & 21 & 12 & 2 & 10 & 6 & 6 & 35 & 22 \\
Ragweed & 42 & 10 & 0 & 0 & 2 & 5 & 52 & 7 \\
Waterhemp & 0 & 0 & 0 & 0 & 15 & 45 & 0 & 60 \\
Redroot Pigweed & 52 & 8 & 0 & 0 & 0 & 0 & 60 & 0 \\
\hline
\end{tabular}

Magnitude of Resistance: 0 = Dead Plants 5 = Alive Plants with no Symptoms.

The same source of seeds was used in both Casselton and Carrington locations. Therefore, the varying degrees of resistance observed at Casselton were also observed at Carrington, as expected. However, the efficacy of the herbicide was noticeably less at the Carrington site. This was because symptomology was seen as early as 2 DAA at the Casselton site but not seen until 6 DAA at the Carrington site. The rates of susceptibility observed at the Carrington location are summarized within Table 4. 
Table 4. Carrington Plant Survival Evaluation at 14 DAA.

\begin{tabular}{ccccccccc}
\hline \multirow{2}{*}{ Species Rating } & \multicolumn{4}{c}{ Magnitude of Resistance } & \multicolumn{3}{c}{ \# Observed } \\
\cline { 2 - 9 } & $\mathbf{0}$ & $\mathbf{1}$ & $\mathbf{2}$ & $\mathbf{3}$ & $\mathbf{4}$ & $\mathbf{5}$ & Susc. & Res. \\
\hline Kochia & 1 & 7 & 17 & 7 & 9 & 19 & 25 & 35 \\
Ragweed & 2 & 3 & 3 & 7 & 10 & 5 & 8 & 22 \\
Waterhemp & 0 & 0 & 0 & 0 & 18 & 42 & 0 & 60 \\
Redroot Pigweed & 40 & 20 & 0 & 0 & 0 & 0 & 60 & 0 \\
\hline
\end{tabular}

Magnitude of Resistance: 0 = Dead Plants 5 = Alive Plants with no Symptoms.

The comparison between the reflectance of glyphosate-resistant vegetation and glyphosate-susceptible vegetation at each of the ten bands provided by the Red-Edge MX Dual Camera system can be seen in Figure 4. Wavelengths $842 \mathrm{~nm}, 705 \mathrm{~nm}$, and $740 \mathrm{~nm}$ from the Red-Edge MX Dual Camera System were selected because large differences in reflectance were found at these wavelengths between glyphosate-resistant vegetation and glyphosate-susceptible vegetation. Wavelengths $842 \mathrm{~nm}, 740 \mathrm{~nm}$, and $705 \mathrm{~nm}$ were subsequently used to create a composite image that served as a third image dataset for classification attempts.

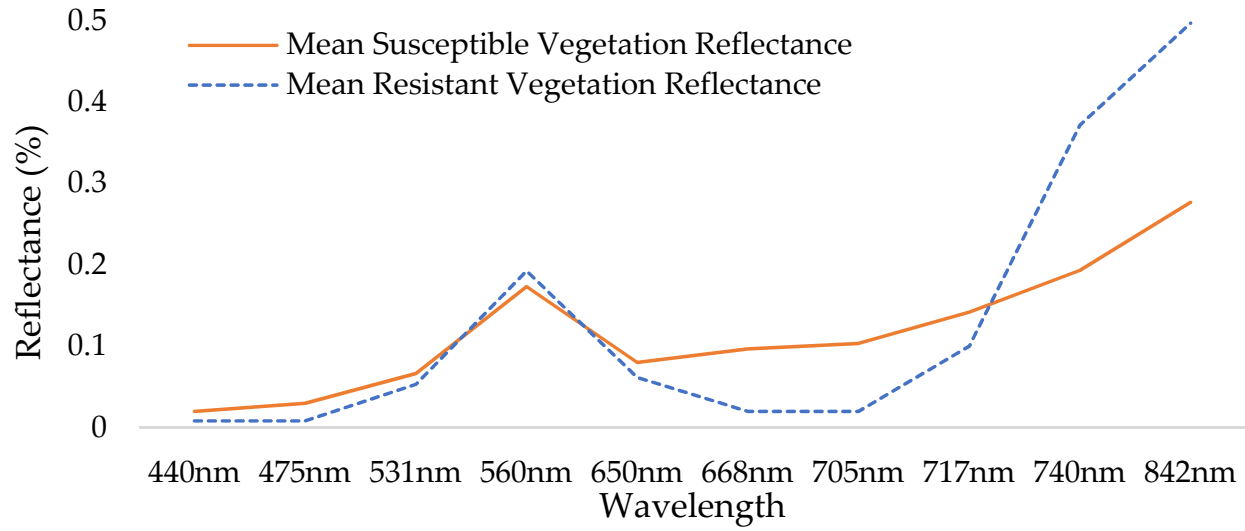

Figure 4. Spectral profile illustrating differences seen at $705 \mathrm{~nm}, 740 \mathrm{~nm}$, and $842 \mathrm{~nm}$ between glyphosate-resistant vegetation and glyphosate-susceptible vegetation within the scene.

A subset of the experiment datasets from the Casselton and Carrington locations at six days after glyphosate application are viewable in Figures 5 and 6. Similar image datasets from every collection period and location were used throughout the experiment.

\subsection{A Discussion on Raster Classification of Glyphosate Resistant and Glyphosate Susceptible Weeds}

The MoR of resistance did not have any variation within the respective species as the waterhemp population was determined to be completely resistant to the glyphosate application while the redroot pigweed population was determined to be completely susceptible to the glyphosate application. That being said, waterhemp and redroot pigweed both are in the same genus of herbaceous plants (Amaranthus L.) commonly referred to as pigweeds [61]. Rather than sacrificing their presence in the study because of their unfavorable resistance statuses, the two species were paired together because of their close relation to each other. The waterhemp served as a glyphosate resistant population and redroot pigweed served as a susceptible population. This approach sacrificed the randomization schemes seen in kochia and ragweed, making thermal classification results unreliable due to spatial temperature differences of areas within the scene. NDVI and wavelength combination of $705 \mathrm{~nm}, 742 \mathrm{~nm}$, and $842 \mathrm{~nm}$ was somewhat reliable as spectral reflectance of vegetation is more consistent despite its location within the scene as all plants received approximately the same amount of sunlight. Improvements in classification accuracy were observed across the total data collection period for each site with wavelength combination $705 \mathrm{~nm}, 740 \mathrm{~nm}$, and $842 \mathrm{~nm}$ from the Red-Edge MX Dual Camera providing the highest accuracy and kappa coefficient results. This effect is expected, as the herbicide is provided 
more time to induce symptomology and gradually desiccate the susceptible population due to the inhibition of stomatal conductance often observed with glyphosate application [20].

(a)
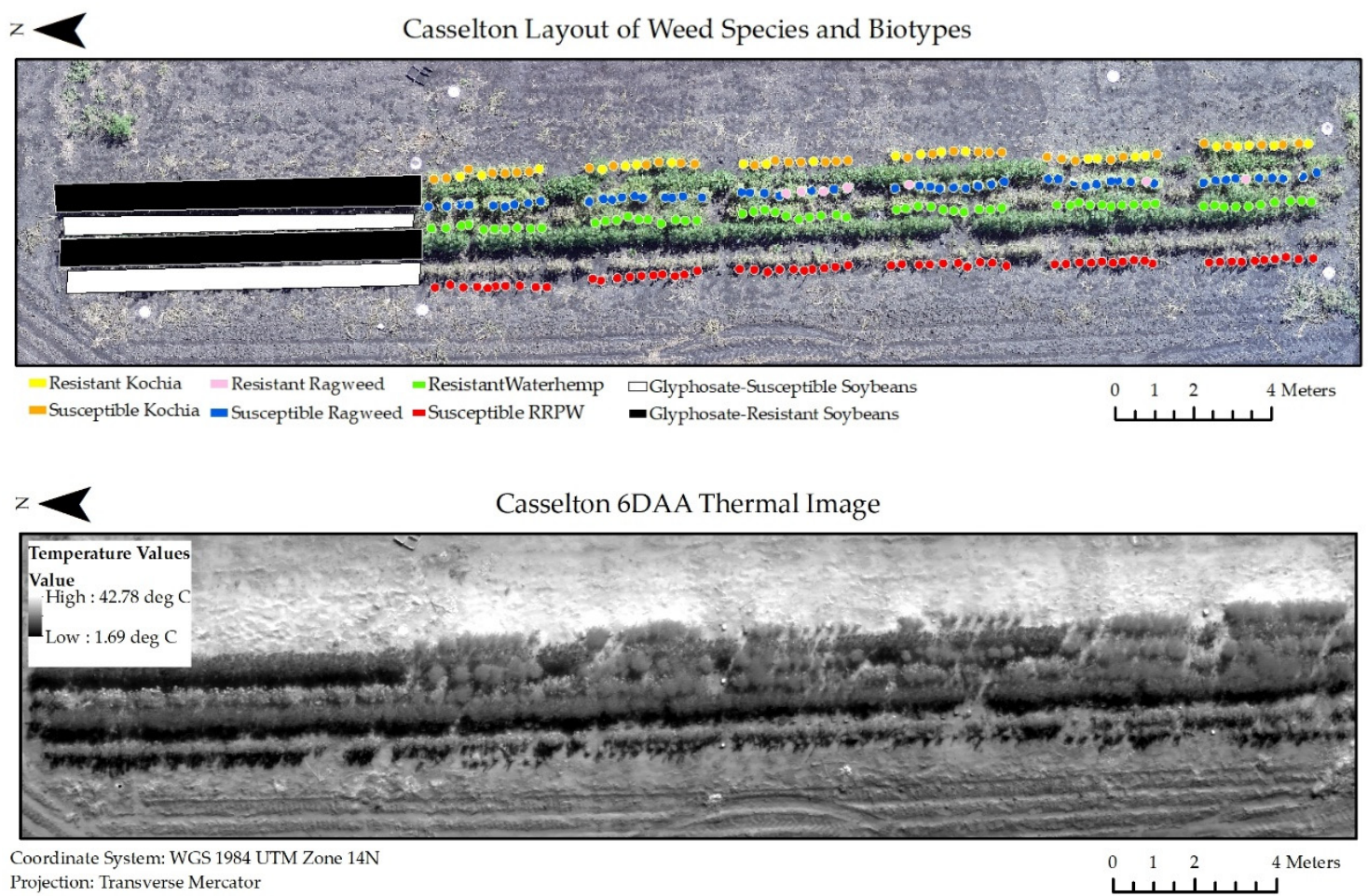

(c)

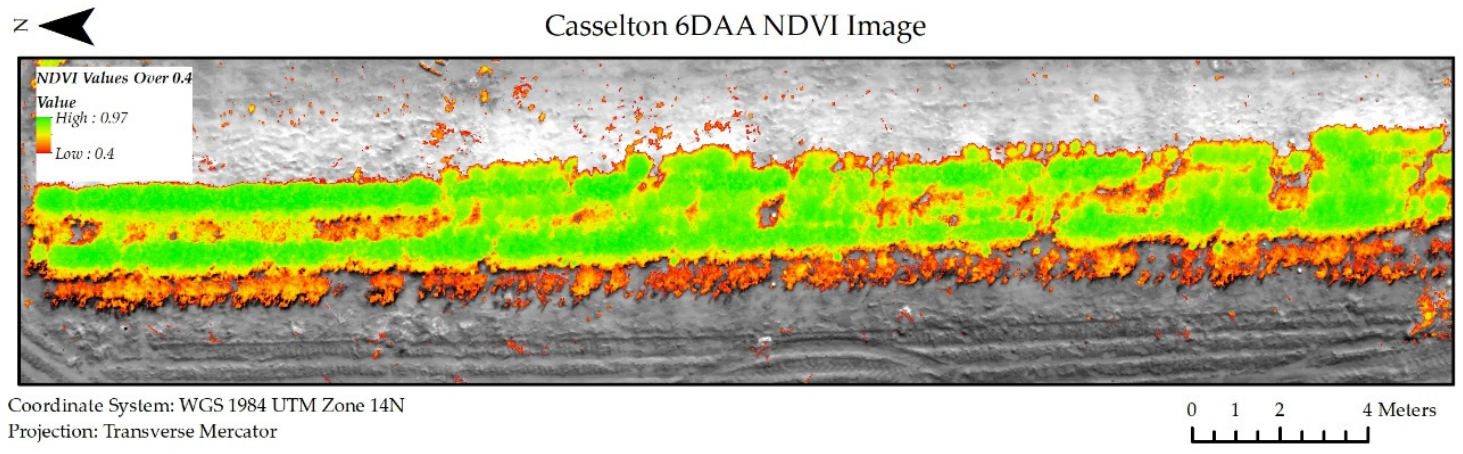

(d)

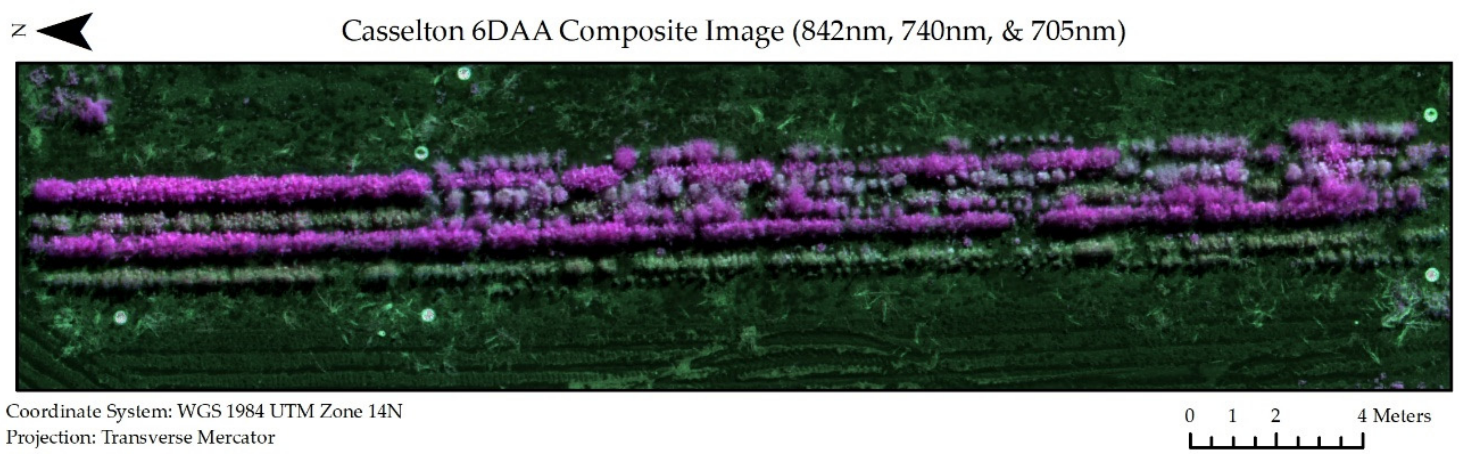

Figure 5. Image datasets from Casselton at 6 days after glyphosate application (6 DAA) used in classification models. (a) Shapefiles denoting species and biotype location within the scene. (b) Thermal image dataset. (c) NDVI image dataset.

(d) Composite Image Dataset for all wavelengths of the multispectral image (RRPW: Redroot Pigweed). 
(a)
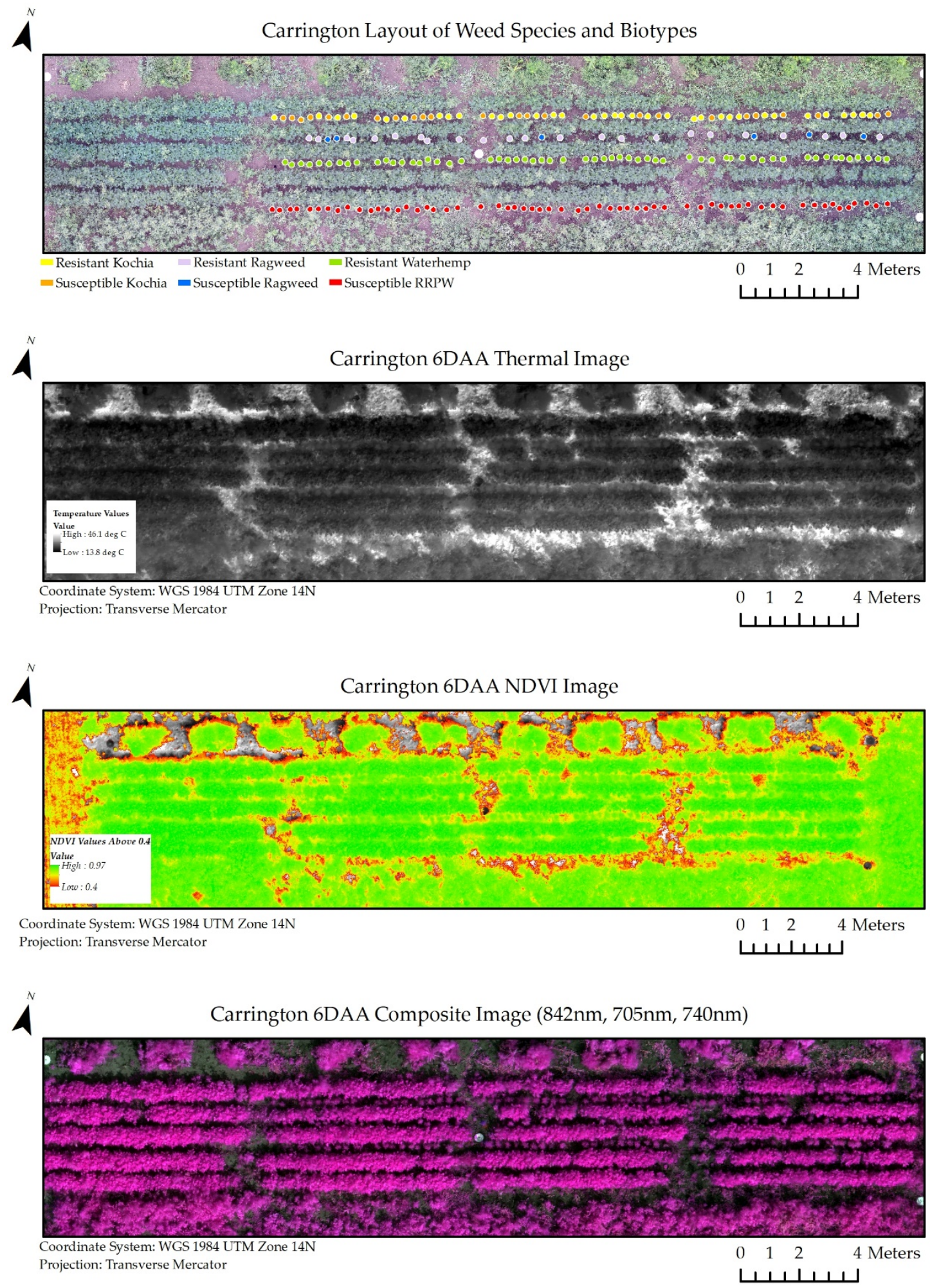

Figure 6. Image datasets from Carrington at 6 days after glyphosate application (6 DAA) used in classification models. (a) Shapefiles denoting species and biotype location within the scene. (b) Thermal image dataset. (c) NDVI image dataset. (d) Composite Image Dataset for all wavelengths of the multispectral image (RRPW: Redroot Pigweed).

\subsection{Classification of Glyphosate-Resistant Kochia}

The kappa coefficient values for kochia at 4 DAA suggested only slight agreement at best between the classification and ground truth fields of wavelength combination $705 \mathrm{~nm}, 740 \mathrm{~nm}$, and $842 \mathrm{~nm}$ at the Casselton location (Table 5). The wavelengths in this 
classification fall within previously reported values in determining glyphosate-resistant kochia [62]. The random trees classifier performed the best at 4 DAA with an accuracy of $62.9 \%$. At 6 DAA, performance slightly improved in all band options. Wavelength combination $705 \mathrm{~nm}, 740 \mathrm{~nm}$, and $842 \mathrm{~nm}$ at the Casselton location with the random trees classifier once again achieved the highest classification accuracy and kappa coefficient results at this time period with values of $74 \%$ and 0.471 , respectively. The 8 DAA kochia classification at Casselton once again improved in performance. The maximum likelihood classifier provided the highest performing result out of all classification attempts with an accuracy of $75.2 \%$ and a kappa coefficient of 0.487 .

Table 5. Kochia Classification Performance Summary.

\begin{tabular}{|c|c|c|c|c|c|c|c|c|c|c|c|}
\hline \multirow[b]{3}{*}{ Band Selection } & \multirow[b]{3}{*}{ Method } & \multicolumn{4}{|c|}{ Carrington } & \multicolumn{6}{|c|}{ Casselton } \\
\hline & & \multicolumn{2}{|c|}{4 DAA $^{1}$} & \multicolumn{2}{|c|}{6 DAA } & \multicolumn{2}{|c|}{4 DAA } & \multicolumn{2}{|c|}{6 DAA } & \multicolumn{2}{|c|}{8 DAA } \\
\hline & & Accuracy & Kappa & Accuracy & Kappa & Accuracy & Kappa & Accuracy & Kappa & Accuracy & Kappa \\
\hline \multirow{3}{*}{ Thermal } & $\mathrm{ML}^{2}$ & 0.591 & 0.089 & 0.576 & 0.151 & 0.576 & 0.133 & 0.577 & 0.161 & 0.579 & 0.17 \\
\hline & $\mathrm{RT}^{3}$ & 0.507 & 0.015 & 0.589 & 0.162 & 0.548 & 0.087 & 0.58 & 0.163 & 0.622 & 0.22 \\
\hline & $\mathrm{SVM}^{4}$ & 0.542 & 0.102 & 0.587 & 0.177 & 0.497 & -0.004 & 0.563 & 0.126 & 0.602 & 0.181 \\
\hline \multirow{3}{*}{ NDVI $^{5}$} & ML & 0.572 & 0.04 & 0.637 & 0.286 & 0.559 & 0.011 & 0.638 & 0.276 & 0.654 & 0.283 \\
\hline & RT & 0.572 & 0.04 & 0.606 & 0.115 & 0.605 & 0.179 & 0.667 & 0.317 & 0.724 & 0.401 \\
\hline & SVM & 0.566 & 0.07 & 0.623 & 0.257 & 0.588 & 0.177 & 0.666 & 0.314 & 0.726 & 0.388 \\
\hline \multirow{3}{*}{$\begin{array}{c}\text { Band Combo } 705 \\
\mathrm{~nm}, 740 \mathrm{~nm}, \& \\
842 \mathrm{~nm}\end{array}$} & ML & 0.584 & 0.167 & 0.673 & 0.3 & 0.609 & 0.224 & 0.691 & 0.385 & 0.752 & 0.487 \\
\hline & RT & 0.591 & 0.134 & 0.727 & 0.453 & 0.629 & 0.258 & 0.74 & 0.471 & 0.742 & 0.463 \\
\hline & SVM & 0.584 & 0.148 & 0.667 & 0.334 & 0.577 & 0.19 & 0.706 & 0.372 & 0.748 & 0.482 \\
\hline
\end{tabular}

${ }^{1}$ DAA: Days After Application, ${ }^{2}$ ML: Maximum Likelihood, ${ }^{3}$ RT: Random Trees, ${ }^{4}$ SVM: Support Vector Machine, ${ }^{5}$ NDVI: Normalized Difference Vegetation Index.

Thermal classifications for kochia were noticeably the lowest performing of the three tested band options. The highest performing thermal classification, which used the random trees method at 8 DAA was outperformed by all NDVI and wavelength combination $705 \mathrm{~nm}, 740 \mathrm{~nm}$, and $842 \mathrm{~nm}$ classifications. This finding suggests that thermal canopy temperature was not a reliable predictor of glyphosate resistance in kochia and that multispectral data should be further investigated.

\subsection{Classification of Glyphosate Resistant Ragweed}

Generally, poor classification performance was seen in ragweed as well. Only 8 ragweed plants at the Carrington site succumbed to the glyphosate application and 22 survived. The weeds showed varying levels of resistance, which likely also reduced the classifier's capability to distinguish between the two biotypes. Contrary to the Casselton site, a large number of susceptible ragweed dominated the Casselton site, leaving only 7 resistant weeds. The natural population of ragweed that was introduced to the study to increase population sizes was determined to be part of the cause for such varying numbers, but it can also be noted that the glyphosate symptomology appeared much sooner and more severely than at Carrington. Despite difficulties in the 4 DAA and 6 DAA data collections, a commendable classification was made via NDVI 8 DAA in Casselton, where the random trees classifier attained an accuracy of $87.2 \%$ with a kappa of 0.413 (Table 6). In order to determine the effectiveness of thermal data to identify glyphosate resistance in ragweed, it is necessary that more data be gathered. 
Table 6. Ragweed Classification Performance Summary.

\begin{tabular}{|c|c|c|c|c|c|c|c|c|c|c|c|}
\hline \multirow[b]{3}{*}{ Band Selection } & \multirow[b]{3}{*}{ Method } & \multicolumn{4}{|c|}{ Carrington } & \multicolumn{6}{|c|}{ Casselton } \\
\hline & & \multicolumn{2}{|c|}{$4 \mathrm{DAA}^{1}$} & \multicolumn{2}{|c|}{6 DAA } & \multicolumn{2}{|c|}{4 DAA } & \multicolumn{2}{|c|}{6 DAA } & \multicolumn{2}{|c|}{8 DAA } \\
\hline & & Accuracy & Kappa & Accuracy & Kappa & Accuracy & Kappa & Accuracy & Kappa & Accuracy & Kappa \\
\hline \multirow{3}{*}{ Thermal } & $\mathrm{ML}^{2}$ & 0.591 & 0.089 & 0.477 & 0.045 & 0.582 & -0.057 & 0.622 & -0.046 & 0.43 & 0.071 \\
\hline & $\mathrm{RT}^{3}$ & 0.507 & 0.015 & 0.643 & 0.25 & 0.568 & 0.13 & 0.514 & 0.051 & 0.627 & 0.119 \\
\hline & $\mathrm{SVM}^{4}$ & 0.542 & 0.102 & 0.484 & 0.06 & 0.592 & 0.052 & 0.442 & 0.02 & 0.562 & 0.055 \\
\hline \multirow{3}{*}{$\mathrm{NDVI}^{5}$} & ML & 0.32 & 0.03 & 0.329 & 0.031 & 0.704 & -0.087 & 0.642 & 0.099 & 0.728 & 0.179 \\
\hline & RT & 0.483 & 0.056 & 0.574 & 0.127 & 0.562 & 0.05 & 0.643 & 0.174 & 0.778 & 0.27 \\
\hline & SVM & 0.441 & 0.022 & 0.565 & 0.119 & 0.54 & 0.066 & 0.689 & 0.124 & 0.872 & 0.413 \\
\hline \multirow{3}{*}{$\begin{array}{c}\text { Band Combo } 705 \\
\mathrm{~nm}, 740 \mathrm{~nm}, \& \\
842 \mathrm{~nm}\end{array}$} & ML & 0.428 & 0.067 & 0.29 & 0.036 & 0.552 & 0.096 & 0.711 & 0.157 & 0.761 & 0.246 \\
\hline & RT & 0.618 & 0.25 & 0.656 & 0.3 & 0.635 & 0.113 & 0.767 & 0.37 & 0.769 & 0.303 \\
\hline & SVM & 0.564 & 0.191 & 0.633 & 0.263 & 0.536 & 0.071 & 0.755 & 0.231 & 0.767 & 0.278 \\
\hline
\end{tabular}

${ }^{1}$ DAA: Days After Application, ${ }^{2}$ ML: Maximum Likelihood, ${ }^{3}$ RT: Random Trees, ${ }^{4}$ SVM: Support Vector Machine, ${ }^{5}$ NDVI: Normalized Difference Vegetation Index.

\subsection{Classification of Glyphosate Resistant Amaranth}

The amaranth dataset (composed of resistant waterhemp and susceptible redroot pigweed) exhibited much higher accuracy and kappa scores for thermal classifications, although these values are likely inflated. The Carrington site's thermal classifications likely received such high accuracy and kappa scores solely because of the two species' spatial location within the scene. The resistant waterhemp population filled the interior of a soybean row with dense vegetation that was near canopy closure. The soybean canopy provided shelter for the waterhemp, while the redroot pigweed was positioned on the outside of a soybean row, where it was directly exposed to sunlight. The presence of shadows over vegetation provide a cooling effect to the waterhemp plant areas. Shaded areas received diffused solar radiation compared to areas in direct sunlight, leading to a significant temperature differential [25]. In addition to the difference in spatial location, the polarizing differences in MoR that were observed could also further cause an easily detectable temperature differential between the two species, where the resistant waterhemp canopies showed cooler temperatures than the susceptible redroot pigweed canopies.

It is possible that the difference in spatial location was not as much of a factor at the Casselton location as sunlight exposure was approximately the same for both species. Due to the north facing orientation of the plot, sunlight was provided parallel to the soybean rows at the time of data collection rather than across dense soybean rows as in Carrington. This reasoning could offer explanation as to why the Carrington location received higher accuracy results than Casselton. Regardless, this approach illustrates the powerful impact of spatial variability of temperature on classification accuracy using thermal sensors. Weeds that were placed only a few feet away from each other exhibited significantly different canopy temperatures because of different levels of exposure to sunlight. While the spatial variability and presence of crops could potentially impact the thermal readings, reflectance values from a multispectral sensor are less susceptible to the same degree of contamination as sunlight reflectance is the value being recorded and not temperature. Therefore, the superior performance shown by the multispectral sensors serves as another indicator that thermal classifications are not reliable. The results of the Amaranth classifications are summarized in Table 7. 
Table 7. Amaranth Classification Performance Summary.

\begin{tabular}{|c|c|c|c|c|c|c|c|c|c|c|c|}
\hline \multirow[b]{3}{*}{ Band Selection } & \multirow[b]{3}{*}{ Method } & \multicolumn{4}{|c|}{ Carrington } & \multicolumn{6}{|c|}{ Casselton } \\
\hline & & \multicolumn{2}{|c|}{4 DAA $^{1}$} & \multicolumn{2}{|c|}{6 DAA } & \multicolumn{2}{|c|}{4 DAA } & \multicolumn{2}{|c|}{6 DAA } & \multicolumn{2}{|c|}{8 DAA } \\
\hline & & Accuracy & Kappa & Accuracy & Kappa & Accuracy & Kappa & Accuracy & Kappa & Accuracy & Kappa \\
\hline \multirow{3}{*}{ Thermal } & $\mathrm{ML}^{2}$ & 0.778 & 0.554 & 0.707 & 0.406 & 0.775 & 0.457 & 0.783 & 0.489 & 0.7 & 0.274 \\
\hline & $\mathrm{RT}^{3}$ & 0.793 & 0.587 & 0.956 & 0.912 & 0.721 & 0.389 & 0.745 & 0.43 & 0.678 & 0.177 \\
\hline & SVM $^{4}$ & 0.796 & 0.592 & 0.92 & 0.84 & 0.79 & 0.474 & 0.796 & 0.499 & 0.651 & 0.278 \\
\hline \multirow{3}{*}{ NDVI $^{5}$} & ML & 0.769 & 0.535 & 0.865 & 0.729 & 0.971 & 0.935 & 0.969 & 0.939 & 0.923 & 0.8 \\
\hline & RT & 0.727 & 0.454 & 0.869 & 0.737 & 0.967 & 0.926 & 0.976 & 0.944 & 0.935 & 0.81 \\
\hline & SVM & 0.779 & 0.558 & 0.861 & 0.722 & 0.972 & 0.936 & 0.98 & 0.954 & 0.919 & 0.796 \\
\hline \multirow{3}{*}{$\begin{array}{c}\text { Band Combo } 705 \\
\mathrm{~nm}, 740 \mathrm{~nm}, \& \\
842 \mathrm{~nm}\end{array}$} & ML & 0.778 & 0.554 & 0.911 & 0.822 & 0.977 & 0.947 & 0.942 & 0.856 & 0.935 & 0.82 \\
\hline & RT & 0.796 & 0.592 & 0.836 & 0.671 & 0.967 & 0.926 & 0.988 & 0.972 & 0.927 & 0.81 \\
\hline & SVM & 0.793 & 0.587 & 0.907 & 0.813 & 0.97 & 0.932 & 0.986 & 0.968 & 0.919 & 0.796 \\
\hline
\end{tabular}

${ }^{1}$ DAA: Days After Application, ${ }^{2}$ ML: Maximum Likelihood, ${ }^{3}$ RT: Random Trees, ${ }^{4}$ SVM: Support Vector Machine, ${ }^{5}$ NDVI: Normalized Difference Vegetation Index.

\subsection{Soybean Observation Results}

An experiment for distinguishing glyphosate-resistant vegetation and glyphosatesusceptible vegetation was made using the conventional Stutsman soybean and Xtend2 Round-Up Ready soybean at the Casselton location. The observation made to investigate the classification accuracy attained when dealing with vegetation with known opposing MoR found that multispectral data generally show better potential for classification between glyphosate-resistant and glyphosate-susceptible vegetation. However, thermal classifications showed higher performance at 4 DAA than NDVI or the Band 579 (Table 8). This finding was unexpected, as thermal classifications for any of the weed species did not exhibit similar performance levels at this time interval. This outlier in classification performance could result from incorporating highly glyphosate-susceptible Stutsman soybean and glyphosate tolerant Xtend 2 Round Up Ready soybean. This degree of difference in resistance status is highly unlikely in natural populations of weeds as resistance to glyphosate is generally conferred at a low MoR ( 2 or 3 ) which is why high doses of herbicide are recommended to impede glyphosate resistance [26]. An additional suggestion for the increased performance is that the increased amount of vegetation area was able to be captured more effectively with the lower resolution thermal camera, thus encouraging segregation between classes [63]. The Zenmuse XT2 thermal camera provided $1.03 \mathrm{~cm} /$ pixel spatial resolution. The average leaf diameter of the soybean plants was $7 \mathrm{~cm}$. The average leaf diameter that belonged to waterhemp and was only $2-3 \mathrm{~cm}$. Therefore, it is possible that there were other reliable thermal signatures captured from soybean canopies than weed canopies [64]. Reliable soybean canopy temperature extraction has proven to be possible with spatial resolutions as high as $0.8 \mathrm{~m}$ when investigating stomatal closure due to drought conditions [18].

Table 8. Casselton Soybean Classification Performance Summary.

\begin{tabular}{|c|c|c|c|c|c|c|c|}
\hline \multirow[b]{2}{*}{ Band Selection } & \multirow[b]{2}{*}{ Method } & \multicolumn{2}{|c|}{$4 \mathrm{DAA}^{1}$} & \multicolumn{2}{|c|}{6 DAA } & \multicolumn{2}{|c|}{8 DAA } \\
\hline & & Accuracy & Kappa & Accuracy & Kappa & Accuracy & Kappa \\
\hline \multirow{3}{*}{ Thermal } & $\mathrm{ML}^{2}$ & 0.942 & 0.88 & 0.82 & 0.62 & 0.886 & 0.76 \\
\hline & $\mathrm{RT}^{3}$ & 0.918 & 0.83 & 0.77 & 0.52 & 0.908 & 0.81 \\
\hline & $\mathrm{SVM}^{4}$ & 0.936 & 0.87 & 0.79 & 0.56 & 0.889 & 0.77 \\
\hline \multirow{3}{*}{ NDVI $^{5}$} & ML & 0.794 & 0.55 & 0.944 & 0.89 & 0.977 & 0.95 \\
\hline & RT & 0.71 & 0.41 & 0.935 & 0.86 & 0.981 & 0.96 \\
\hline & SVM & 0.742 & 0.45 & 0.941 & 0.88 & 0.983 & 0.96 \\
\hline \multirow{3}{*}{$\begin{array}{l}\text { Band Combo } 705 \mathrm{~nm} \text {, } \\
740 \mathrm{~nm}, \& 842 \mathrm{~nm}\end{array}$} & ML & 0.824 & 0.636 & 0.953 & 0.9 & 0.987 & 0.972 \\
\hline & RT & 0.82 & 0.64 & 0.907 & 0.808 & 0.978 & 0.954 \\
\hline & SVM & 0.824 & 0.65 & 0.963 & 0.922 & 0.981 & 0.959 \\
\hline
\end{tabular}

${ }^{1}$ DAA: Days After Application, ${ }^{2}$ ML: Maximum Likelihood, ${ }^{3}$ RT: Random Trees, ${ }^{4}$ SVM: Support Vector Machine, ${ }^{5}$ NDVI: Normalized

Difference Vegetation Index. 
Overall, determining glyphosate-resistant weed species with UAV thermal sensing was not possible in field conditions. Our previous study on thermal sensing for glyphosateresistant weed identification under greenhouse conditions also produced similar results and raised questions on how to improve its overall performance for future studies [22]. The experiment conditions and some of the parameters could be readjusted to further improve the performance such as consideration of different experiment size, UAV flight parameters, thermal sensors, and daylight conditions $[65,66]$. In addition, complementary measurements to thermal measurements could improve the overall efficiency of determining glyphosate-resistant weed species [49-51]. In this case, the multispectral measurements were more reliable than the thermal measurements on determining glyphosate resistance status, therefore a combined analysis of the two could provide more accurate results. Furthermore, shading issue in remote sensing is a well-known problem, especially for thermal sensing [67]. Improving abovementioned parameters could improve overall performance of UAV thermal sensing as well as help eliminate the concerns on temperature differences due to uneven solar radiance [68].

The multispectral sensing technology was specifically introduced in this research to explore the reliability of glyphosate-resistant weed identification in-field condition. Using various imaging technologies to identify weed in precision agriculture had been investigated by other researchers for at least a decade. In 2001, Rath and Hemming investigated computer vision-based weed identification under controlled lighting in-field conditions. The experiments showed that color features could help increase classification accuracy [69]. Later in 2016, Ortiz et al. used UAV imagery to extract patterns and features between and within crop row for weed mapping. The results showed that more than $91.5 \%$ of weed objects were classified in the sunflower field [70]. One of the most recent research that focused on weed mapping through UAV tested four independent classification algorithms for the creation of weed maps by combining automatic and manual methods for weed classification. The results showed that the automatic objectbased classification method achieved the highest classification accuracy, resulting in an overall accuracy of $89.0 \%$ for subset " $\mathrm{A}$ " and $87.1 \%$ for subset " $\mathrm{B}$ ". With all the research mentioned above, they were more focused on the image detection methods, which is critical for weed identification [71]. However, in our research, we did not only focus on the method for image recognition and classification, but also on classification of glyphosate-resistant and glyphosate susceptible weed attributes. The latter focus served as the main objective for this research, which made significant contribution to weed control publications.

\section{Conclusions}

Cost-effective weed management strategy without promoting glyphosate-resistant weed biotypes requires distinguishing resistant and susceptible biotypes in the field conditions. Unmanned Aerial Vehicle (UAV)-assisted thermal and multispectral remote sensing could improve distinguishing glyphosate-susceptible and glyphosate-resistant weed populations based on canopy temperature and deep learning driven weed identification algorithms. However, the thermal imagery as a predictor for glyphosate resistance within weed populations did not perform well in this study. While technological advancements have provided increased resolutions in thermal systems, it was observed that higher resolution is needed to make thermal data more scalable. Normalized Difference Vegetation Index (NDVI) and a composite image comprised of $842 \mathrm{~nm}, 705 \mathrm{~nm}$, and $740 \mathrm{~nm}$ wavelength imagery managed to provide better classification results than thermal data provided. However, classifications that performed within a single species to segregate glyphosateresistant and glyphosate-susceptible biotypes of weeds still were not definitive. The high classification accuracy obtained in the cases of amaranth and soybean plants supports the notion that extreme differences in Mode of Resistance (MoR) are necessary for any reliable attempt to identify glyphosate-resistant vegetation regardless of using multispectral or thermal data as a predictor. Regardless of the limitations in the experiment design, the 
research could be a useful step towards identifying potential methods for further weed identification studies.

Author Contributions: Conceptualization, A.E. and X.S.; methodology, A.E.; software, A.E. and Y.Z.; validation, A.E., Y.Z. and C.K.; formal analysis, A.E.; investigation, A.E.; resources, X.S., Y.Z., M.O. and K.H.; data curation, A.E.; writing-original draft preparation, A.E.; writing-review and editing, C.K., Y.Z., M.O., K.H. and X.S.; visualization, A.E.; supervision, X.S.; project administration, X.S.; funding acquisition, X.S. All authors have read and agreed to the published version of the manuscript.

Funding: This material is based upon work partially supported by the U.S. Department of Agriculture, agreement number 58-6064-8-023. Any opinions, finding, conclusions or recommendations expressed in this publication are those of the author(s) and do not necessarily reflect the view of the U.S. Department of Agriculture. This research was also partially supported by the North Dakota State University Agricultural Experiment Station Precision Agriculture Fund FARG080010.

Institutional Review Board Statement: Not applicable.

Informed Consent Statement: Not applicable.

Data Availability Statement: The data presented in this study are available on request from the corresponding author. The data are not publicly available due to data format and size.

Conflicts of Interest: The authors declare no conflict of interest.

\section{References}

1. Green, J.M. The benefits of herbicide-resistant crops. Pest Manag. Sci. 2012, 68, 1323-1331. [CrossRef] [PubMed]

2. Oerke, E.C. Crop losses to pests. J. Agric. Sci. 2006, 144, 31-43. [CrossRef]

3. Soltani, N.; Dille, J.A.; Burke, I.C.; Everman, W.J.; VanGessel, M.J.; Davis, V.M.; Sikkema, P.H. Potential Corn Yield Losses from Weeds in North America. Weed Technol. 2016, 30, 979-984. [CrossRef]

4. Evans, J.A.; Tranel, P.J.; Hager, A.G.; Schutte, B.; Wu, C.; Chatham, L.A.; Davis, A.S. Managing the evolution of herbicide resistance. Pest Manag. Sci. 2016, 72, 74-80. [CrossRef] [PubMed]

5. Christophers, M.J. Genetic Aspects of Herbicide-Resistant Weed Management. Weed Technol. 1999, 13, 647-652. [CrossRef]

6. Pollegioni, L.; Schonbrunn, E.; Siehl, D. Molecular basis of glyphosate resistance-Different approaches through protein engineering. FEBS J. 2011, 278, 2753-2766. [CrossRef]

7. Gage, K.L.; Krausz, R.F.; Walters, S.A. Emerging Challenges for Weed Management in Herbicide-Resistant Crops. Agriculture 2019, 9, 180. [CrossRef]

8. Schütte, G.; Eckerstorfer, M.; Rastelli, V.; Reichenbecher, W.; Restrepo-Vassalli, S.; Ruohonen-Lehto, M.; Saucy, A.-G.W.; Mertens, M. Herbicide resistance and biodiversity: Agronomic and environmental aspects of genetically modified herbicide-resistant plants. Environ. Sci. Eur. 2017, 29, 5. [CrossRef]

9. Hartzler, R. The Cost of Herbicide Resistance. Available online: https://crops.extension.iastate.edu/blog/bob-hartzler/costherbicide-resistance (accessed on 8 December 2019).

10. Pause, M.; Raasch, F.; Marrs, C.; Csaplovics, E. Monitoring Glyphosate-Based Herbicide Treatment Using Sentinel-2 Time Series-A Proof-of-Principle. Remote Sens. 2019, 11, 2541. [CrossRef]

11. Kanissery, R.; Gairhe, B.; Kadyampakeni, D.; Batuman, O.; Alferez, F. Glyphosate: Its Environmental Persistence and Impact on Crop Health and Nutrition. Plants 2019, 8, 499. [CrossRef]

12. Gomes, M.P.; Le Manac'h, S.G.; Hénault-Ethier, L.; Labrecque, M.; Lucotte, M.; Juneau, P. Glyphosate-Dependent Inhibition of Photosynthesis in Willow. Front. Plant Sci. 2017, 8, 207. [CrossRef] [PubMed]

13. Gaines, T.A.; Duke, S.O.; Morran, S.; Rigon, C.A.G.; Tranel, P.J.; Küpper, A.; Dayan, F.E. Mechanisms of evolved herbicide resistance. J. Biol. Chem. 2020, 295, 10307-10330. [CrossRef] [PubMed]

14. Reddy, K.N.; Huang, Y.; Lee, M.A.; Nandula, V.K.; Fletcher, R.S.; Thomson, S.J.; Zhao, F. Glyphosate-resistant and glyphosatesusceptible Palmer amaranth (Amaranthus palmeri S. Wats.): Hyperspectral reflectance properties of plants and potential for classification. Pest Manag. Sci. 2014, 70, 1910-1917. [CrossRef] [PubMed]

15. Shirzadifar, A.; Bajwa, S.; Nowatzki, J.; Bazrafkan, A. Field identification of weed species and glyphosate-resistant weeds using high resolution imagery in early growing season. Biosyst. Eng. 2020, 200, 200-214. [CrossRef]

16. Xu, S.; Hossain, M.M.; Lau, B.B.Y.; To, T.Q.; Rawal, A.; Aldous, L. Total quantification and extraction of shikimic acid from star anise (llicium verum) using solid-state NMR and cellulose-dissolving aqueous hydroxide solutions. Sustain. Chem. Pharm. 2017, 5, 115-121. [CrossRef]

17. Singh, V.; Rana, A.; Bishop, M.; Filippi, A.M.; Cope, D.; Rajan, N.; Bagavathiannan, M. Chapter Three-Unmanned aircraft systems for precision weed detection and management: Prospects and challenges. In Advances in Agronomy; Sparks, D.L., Ed.; Academic Press: Cambridge, MA, USA, 2020; Volume 159, pp. 93-134. 
18. Shirzadifar, A. Identification of Weed Species and Glyphosate-Resistant Weeds Using High Resolution UAS Images. Ph.D. Thesis, 2018. Available online: https:/ /library.ndsu.edu/ir/handle/10365/29304 (accessed on 5 November 2021).

19. Stoll, M.; Hamlyn, G.J. Thermal imaging as a viable tool for monitoring plant stress. OENO One 2007, 41, 77-84. [CrossRef]

20. Picoli, G.; Carbonari, C.; Matos, A.; Rodrigues, L.; Velini, E. Influence of glyphosate on susceptible and resistant ryegrass populations to herbicide. Planta Daninha 2017, 35, e017163391. [CrossRef]

21. Gonzalez-Dugo, V.; Lopez-Lopez, M.; Espadafor, M.; Orgaz, F.; Testi, L.; Zarco-Tejada, P.; Lorite, I.J.; Fereres, E. Transpiration from canopy temperature: Implications for the assessment of crop yield in almond orchards. Eur. J. Agron. 2019, 105, 78-85. [CrossRef]

22. Eide, A.; Zhang, Y.; Koparan, C.; Stenger, J.; Ostlie, M.; Howatt, K.; Bajwa, S.; Sun, X. Image based thermal sensing for glyphosate resistant weed identification in greenhouse conditions. Comput. Electron. Agric. 2021, 188, 106348. [CrossRef]

23. Johnson, W.G.; Owen, M.D.K.; Kruger, G.R.; Young, B.G.; Shaw, D.R.; Wilson, R.G.; Wilcut, J.W.; Jordan, D.L.; Weller, S.C. U.S. Farmer Awareness of Glyphosate-Resistant Weeds and Resistance Management Strategies. Weed Technol. 2009, $23,308-312$. [CrossRef]

24. Foresman, C.; Glasgow, L. US grower perceptions and experiences with glyphosate-resistant weeds. Pest Manag. Sci. 2008, 64, 388-391. [CrossRef]

25. Beckie, H.J.; Sikkema, P.H.; Soltani, N.; Blackshaw, R.E.; Johnson, E.N. Environmental Impact of Glyphosate-Resistant Weeds in Canada. Weed Sci. 2014, 62, 385-392. [CrossRef]

26. Deng, L.; Mao, Z.; Li, X.; Hu, Z.; Duan, F.; Yan, Y. UAV-based multispectral remote sensing for precision agriculture: A comparison between different cameras. ISPRS J. Photogramm. Remote Sens. 2018, 146, 124-136. [CrossRef]

27. Roslim, M.H.M.; Juraimi, A.S.; Che'Ya, N.N.; Sulaiman, N.; Manaf, M.N.H.A.; Ramli, Z.; Motmainna, M. Using remote sensing and an unmanned aerial system for weed management in agricultural crops: A review. Agronomy 2021, 11, 1809. [CrossRef]

28. Qi, H.; Wu, Z.; Zhang, L.; Li, J.; Zhou, J.; Jun, Z.; Zhu, B. Monitoring of peanut leaves chlorophyll content based on drone-based multispectral image feature extraction. Comput. Electron. Agric. 2021, 187, 106292. [CrossRef]

29. The Science Behind MicaSense-MicaSense. 2017. Available online: https://micasense.com/the-science-behind-micasense/ (accessed on 5 November 2021).

30. Liu, J.; Chen, P.; Xu, X. Estimating wheat coverage using multispectral images collected by unmanned aerial vehicles and a new sensor. In Proceedings of the 2018 7th International Conference on Agro-Geoinformatics (Agro-Geoinformatics), Hangzhou, China, 6-9 August 2018; pp. 1-5.

31. Dual Camera Imaging System-MicaSense. Available online: https://micasense.com/dual-camera-system/ (accessed on 5 November 2021).

32. Chawade, A.; Ham, J.v.; Blomquist, H.; Bagge, O.; Alexandersson, E.; Ortiz, R. High-Throughput Field-Phenotyping Tools for Plant Breeding and Precision Agriculture. Agronomy 2019, 9, 258. [CrossRef]

33. Sankaran, S.; Khot, L.R.; Espinoza, C.Z.; Jarolmasjed, S.; Sathuvalli, V.R.; Vandemark, G.J.; Miklas, P.N.; Carter, A.H.; Pumphrey, M.O.; Knowles, N.R.; et al. Low-altitude, high-resolution aerial imaging systems for row and field crop phenotyping: A review. Eur. J. Agron. 2015, 70, 112-123. [CrossRef]

34. Xu, R.; Li, C.; Paterson, A.H. Multispectral imaging and unmanned aerial systems for cotton plant phenotyping. PLoS ONE 2019, 14, e0205083. [CrossRef] [PubMed]

35. Fernández, C.I.; Leblon, B.; Haddadi, A.; Wang, K.; Wang, J. Potato Late Blight Detection at the Leaf and Canopy Levels Based in the Red and Red-Edge Spectral Regions. Remote Sens. 2020, 12, 1292. [CrossRef]

36. Thompson, L.J.; Puntel, L.A. Transforming Unmanned Aerial Vehicle (UAV) and Multispectral Sensor into a Practical Decision Support System for Precision Nitrogen Management in Corn. Remote Sens. 2020, 12, 1597. [CrossRef]

37. Dyrmann, M.; Mortensen, A.; Midtiby, H.; Jørgensen, R. Pixel-Wise Classification of Weeds and Crops in Images by Using a Fully Convolutional Neural Network. 2016. Available online: https:/ /www.semanticscholar.org/paper/Pixel-wise-classification-ofweeds-and-crops-in-by-Dyrmann-Mortensen/393d4bbb92e5ce5e308ad61a771cc2015b342d5d (accessed on 5 November 2021).

38. Crusiol, L.G.T.; Nanni, M.R.; Furlanetto, R.H.; Sibaldelli, R.N.R.; Cezar, E.; Mertz-Henning, L.M.; Nepomuceno, A.L.; Neumaier, N.; Farias, J.R.B. UAV-based thermal imaging in the assessment of water status of soybean plants. Int. J. Remote Sens. 2019, 41, 3243-3265. [CrossRef]

39. Zhang, W.; Yi, S.-h.; Qin, Y.; Shangguan, D.-h.; Qin, Y. Analysis of features and influencing factors of alpine meadow surface temperature based on UAV thermal thermography. Acta Prataculturae Sin. 2021, 30, 15.

40. Pineda, M.; Barón, M.; Pérez-Bueno, M.-L. Thermal imaging for plant stress detection and phenotyping. Remote Sens. 2021, 13, 68. [CrossRef]

41. Awais, M.; Li, W.; Cheema, M.J.M.; Hussain, S.; AlGarni, T.S.; Liu, C.; Ali, A. Remotely sensed identification of canopy characteristics using UAV-based imagery under unstable environmental conditions. Environ. Technol. Innov. 2021, $22,101465$. [CrossRef]

42. Sagan, V.; Maimaitijiang, M.; Sidike, P.; Eblimit, K.; Peterson, K.T.; Hartling, S.; Esposito, F.; Khanal, K.; Newcomb, M.; Pauli, D.; et al. UAV-Based High Resolution Thermal Imaging for Vegetation Monitoring, and Plant Phenotyping Using ICI 8640 P, FLIR Vue Pro R 640, and thermoMap Cameras. Remote Sens. 2019, 11, 330. [CrossRef]

43. Botyanszka, L. A Review of Imaging and Sensing Technologies for Field Phenotyping. Acta Hortic. Regiotect. 2021, $24,58-69$. [CrossRef] 
44. Gelasakis, A.I.; Kalogianni, A.I.; Moschovas, M.; Tsimpouri, E.; Pnevmatikos, T.; Bossis, I.; Arsenos, G.; Simitzis, P. Evaluation of Infrared Thermography for the Detection of Footrot and White Line Disease Lesions in Dairy Sheep. Vet. Sci. 2021, 8, 219. [CrossRef]

45. Zhang, C.; Valente, J.; Kooistra, L.; Guo, L.; Wang, W. Orchard management with small unmanned aerial vehicles: A survey of sensing and analysis approaches. Precis. Agric. 2021, 22, 2007-2052. [CrossRef]

46. Ballester, C.; Zarco-Tejada, P.J.; Nicolás, E.; Alarcón, J.J.; Fereres, E.; Intrigliolo, D.S.; Gonzalez-Dugo, V. Evaluating the performance of xanthophyll, chlorophyll and structure-sensitive spectral indices to detect water stress in five fruit tree species. Precis. Agric. 2018, 19, 178-193. [CrossRef]

47. Gonzalez-Dugo, V.; Zarco-Tejada, P.; Nicolás, E.; Nortes, P.A.; Alarcón, J.J.; Intrigliolo, D.S.; Fereres, E. Using high resolution UAV thermal imagery to assess the variability in the water status of five fruit tree species within a commercial orchard. Precis. Agric. 2013, 14, 660-678. [CrossRef]

48. Gómez-Candón, D.; Virlet, N.; Labbé, S.; Jolivot, A.; Regnard, J.-L. Field phenotyping of water stress at tree scale by UAV-sensed imagery: New insights for thermal acquisition and calibration. Precis. Agric. 2016, 17, 786-800. [CrossRef]

49. Zhu, W.; Sun, Z.; Huang, Y.; Yang, T.; Li, J.; Zhu, K.; Zhang, J.; Yang, B.; Shao, C.; Peng, J.; et al. Optimization of multi-source UAV RS agro-monitoring schemes designed for field-scale crop phenotyping. Precis. Agric. 2021, 22, 1768-1802. [CrossRef]

50. Calderón, R.; Montes-Borrego, M.; Landa, B.B.; Navas-Cortés, J.A.; Zarco-Tejada, P.J. Detection of downy mildew of opium poppy using high-resolution multi-spectral and thermal imagery acquired with an unmanned aerial vehicle. Precis. Agric. 2014, 15, 639-661. [CrossRef]

51. Bellvert, J.; Zarco-Tejada, P.J.; Girona, J.; Fereres, E. Mapping crop water stress index in a 'Pinot-noir' vineyard: Comparing ground measurements with thermal remote sensing imagery from an unmanned aerial vehicle. Precis. Agric. 2014, 15, 361-376. [CrossRef]

52. Martínez, J.; Egea, G.; Agüera, J.; Pérez-Ruiz, M. A cost-effective canopy temperature measurement system for precision agriculture: A case study on sugar beet. Precis. Agric. 2017, 18, 95-110. [CrossRef]

53. Ohana-Levi, N.; Ben-Gal, A.; Peeters, A.; Termin, D.; Linker, R.; Baram, S.; Raveh, E.; Paz-Kagan, T. A comparison between spatial clustering models for determining N-fertilization management zones in orchards. Precis. Agric. 2021, 22, 99-123. [CrossRef]

54. Zhao, B.; Adama, T.; Ata-Ul-Karim, S.T.; Guo, Y.; Liu, Z.; Xiao, J.; Liu, Z.; Qin, A.; Ning, D.; Duan, A. Recalibrating plant water status of winter wheat based on nitrogen nutrition index using thermal images. Precis. Agric. 2021. [CrossRef]

55. Delavarpour, N.; Koparan, C.; Nowatzki, J.; Bajwa, S.; Sun, X. A Technical Study on UAV Characteristics for Precision Agriculture Applications and Associated Practical Challenges. Remote Sens. 2021, 13, 1204. [CrossRef]

56. Prochnow, N.D.; Lunde, N.J.; Terry, W.J.; Opdahl, D.P. Soil Survey of Cass County Area, North Dakota; Soil Conversation Service, United States Department of Agriculture: Washington, DC, USA, 1985.

57. Morrison, M. Soil Survey of Foster County, North Dakota; Soil Conversation Service, United States Department of Agriculture: Washington, DC, USA, 1995.

58. Cortes, C.; Vapnik, V. Support-vector networks. Mach. Learn. 1995, 20, 273-297. [CrossRef]

59. Enders, C.K. Maximum Likelihood Estimation. In Encyclopedia of Statistics in Behavioral Science; 2005. Available online: https: / / onlinelibrary.wiley.com/doi/10.1002/0470013192.bsa174 (accessed on 5 November 2021).

60. Breiman, L. Random Forests. Mach. Learn. 2001, 45, 5-32. [CrossRef]

61. Ikley, J.; Jenks, B. Identification, Biology and Control of Palmer Amaranth and Waterhemp in North Dakota; Research Extention; North Dakota State University: Fargo, ND, USA, 2019.

62. Paul, W.N.; Joseph, A.S.; Prashant, J.; Bryan, S.; Andrew, D.; Vipan, K. Discrimination of herbicide-resistant kochia with hyperspectral imaging. J. Appl. Remote Sens. 2018, 12, 1-10. [CrossRef]

63. Way, R.G.; Lapalme, C.M. Does tall vegetation warm or cool the ground surface? Constraining the ground thermal impacts of upright vegetation in northern environments. Environ. Res. Lett. 2021, 16, 054077. [CrossRef]

64. Leigh, A.; Sevanto, S.; Close, J.D.; Nicotra, A.B. The influence of leaf size and shape on leaf thermal dynamics: Does theory hold up under natural conditions? Plant Cell Environ. 2017, 40, 237-248. [CrossRef] [PubMed]

65. Sobrino, J.A.; Julien, Y. Time Series Corrections and Analyses in Thermal Remote Sensing. In Thermal Infrared Remote Sensing: Sensors, Methods, Applications; Kuenzer, C., Dech, S., Eds.; Springer: Dordrecht, The Netherlands, 2013; pp. $267-285$.

66. Jin, M.; Liang, S. An Improved Land Surface Emissivity Parameter for Land Surface Models Using Global Remote Sensing Observations. J. Clim. 2006, 19, 2867-2881. [CrossRef]

67. Gillies, R.R.; Carlson, T.N. Thermal Remote Sensing of Surface Soil Water Content with Partial Vegetation Cover for Incorporation into Climate Models. J. Appl. Meteorol. Climatol. 1995, 34, 745-756. [CrossRef]

68. Kawamura, K.; Watanabe, N.; Sakanoue, S.; Inoue, Y. Estimating forage biomass and quality in a mixed sown pasture based on partial least squares regression with waveband selection. Grassl. Sci. 2008, 54, 131-145. [CrossRef]

69. Hemming, J.; Rath, T. PA-Precision agriculture: Computer-vision-based weed identification under field conditions using controlled lighting. J. Agric. Eng. Res. 2001, 78, 233-243. [CrossRef]

70. Pérez-Ortiz, M.; Peña, J.M.; Gutiérrez, P.A.; Torres-Sánchez, J.; Hervás-Martínez, C.; López-Granados, F. Selecting patterns and features for between-and within-crop-row weed mapping using UAV-imagery. Expert Syst. Appl. 2016, 47, 85-94. [CrossRef]

71. Gašparović, M.; Zrinjski, M.; Barković, Đ.; Radočaj, D. An automatic method for weed mapping in oat fields based on UAV imagery. Comput. Electron. Agric. 2020, 173, 105385. [CrossRef] 